\title{
Estimation of Arch Width in first Permanent Molar Tooth in the Normal Occlusion in Bangladeshi Population
}

\section{Rahman MM${ }^{1}$ BDS, FCPS and Hossain MZ $^{2}$ BDS, PhD}

\begin{abstract}
Objective: To estimate the arch width in first permanent molar tooth in the normal occlusion of Bangladeshi population.

Method: This cross sectional study was conducted among the students of Dhaka Dental College \& Hospital, Mirpur14, Dhaka-1206. Total number of subjects were hundred, among them fifty were male and fifty were female .Mean age was 23.3 years. The study was conducted from October-2004 to September -2007.

Results: The inter molar arch width in male upper jaws were $36.15 \mathrm{~mm}, 43.45 \mathrm{~mm}$, $53.82 \mathrm{~mm}$ respectively and in lower jaw these were $27.2 \mathrm{~mm}, 36.01 \mathrm{~mm}$ and $46.55 \mathrm{~mm}$. The transverse values in female upper jaw were $34.01 \mathrm{~mm}$, $41.26 \mathrm{~mm} 51.43 \mathrm{~mm}$ respectively and in lower jaw these were $26.12 \mathrm{~mm}, 33.84 \mathrm{~mm}$ and $44.31 \mathrm{~mm}$.

Conclusion: The idea of a single arch width could not be substantiated in the study. But the result of the study might help clinicians to define normal arch width and their variations more precisely. However, there are scopes left for the researchers to work further over the issue. (Ban J Orthod \& Dentofac Orthop, April 2011; Vol-1, No. 2, 5-8)
\end{abstract}

\section{INTRODUCTION}

Occlusion of the teeth means the relationship which the teeth of one arch occlude to the teeth of the other arch when the jaws are closed into maximum cuspal occlusion. An occlusion which satisfies the requirements of function and aesthetics, even though there may minor irregularities of individual teeth, may be accepted as normal occlusion ${ }^{1}$. The key teeth for this classification are the permanent first molars. The mesiobuccal cusp of the first molar should occlude in mesiobuccal groove of the mandibular first permanent molar. Normal occlusion usually involves occlusal contact, alignment of teeth, over jet, overbite, arrangement and relationship of teeth between the arches and relationship of teeth to osseous structures. It should include not only a range of anatomically acceptable values but also physiological adaptability $^{2}$. Normal occlusion of the dentition exhibits a range of values of the arch width. The range of these values depend on various factors, such as-height, weight, sex, race ,food habit ,morphological pattern of dentition, etc. The values of these measurement change through out the dentition .On examination of the deciduous and permanent dentition, arch width increases. ${ }^{3,4}$ In permanent dentition, these changes appear to develop most rapidly in teens and twenties. After twenty these change were minimum. Variation of these measurements cause malocclusion. According to Ashley-crowding occur due to deficiency in arch width than arch length. ${ }^{6,7}$ Thus this study helps in classification, diagnosis and treatment planning of the various type of Orthodontic problem pattern of dentition.

\section{MATERIAL AND METHOD}

A cross sectional type of study carried out to evaluate the " arch width in first permanent molar region in normal occlusion" based on Ashley Howe's analysis, Bolton analysis, Carey's analysis and Pont's analysis. The study was carried out in the
Department of orthodontics, Dhaka Dental College and hospital, Mirpur-14, Dhaka-1206. The eligible samples were those who were diagnosed as a normal occlusion. The samples were the student of Dhaka Dental College and the mean age of samples were23.3 years.

All subjects were selected for this study according to the criteria of normal occlusion. The inclusion criteria were as follows: Angle class- 1 molar relationships, Overbite $4 \mathrm{~mm}$, Over jet $3 \mathrm{~mm}$, a full complement of permanent teeth and minimal total arch crowding or spacing $(<3 \mathrm{~mm})$. Minimal rotation and minimal attritions. Without midline deviations. Total duration of study was from October 2004- September-2007.

Study Procedure: Each of the sample was evaluated by clinical examination and model analysis. The record of 50 female and 50 male sample were selected. All measurement were recorded. The parameters measured were defined as follows:

Arch width at molar region: Arch widths were measured from Central fossa of the right sided first permanent molar to central fossa of the left sided first permanent molar. Mesio buccal groove of the right sided first permanent molar to mesio buccal groove of the left sided first permanent molar and tip of the mesio buccal cusp of right sided first permanent molar to the mesio buccal cusp of the left sided first permanent molar.

Methods of data collection: All data were collected from each sample according to the study procedure, in respect of inclusion criteria. After collection of data, the obtained data were checked, verified, edited and coded. The data were entered into a personal computer using the program SPSS. Entered data were cleaned, edited, and appropriate statistical test were done depending on the distribution of the data.

${ }^{1}$ Lecturer, Department of Orthodontics and Dentofacial Orthopedics Dhaka Dental College. ${ }^{2}$ This study was supervised by Prof. \& Head, Dept. 


\section{RESULTS}

This study was conducted among 100 students of Dhaka Dental College \& Hospital. The occlusion of these student were normal occlusion. Among them fifty were male students and fifty were female students. The age ranges of this students were from 20 to 25 years.

Inter molar arch width (mesiobuccal cusp tip): In upper jaw the mean value in the mesiobuccal cusp tip in case of male was $53.82 \mathrm{~mm}$ with standard deviation ( \pm ) $2.92 \mathrm{~mm}$ and in lower jaw, mean value was $46.55 \mathrm{~mm}$ with standard deviation $( \pm) 3.61 \mathrm{~mm}$. In case of female, in upper jaw the mean value was $51.43 \mathrm{~mm}$ with standard deviation $( \pm$ ) 3.07and in lower jaw the mean value was $44.31 \mathrm{~mm}$ with standard deviation $( \pm) 2.74 \mathrm{~mm}$.
Inter molar arch width (from central fossa to central fossa): The mean value of upper jaw in malesample was $49.18 \mathrm{~mm}$ with standard deviation $( \pm$ ) $2.14 \mathrm{mmand}$ in lower jaw, the mean value was $42.87 \mathrm{~mm}$ with standard deviation $( \pm) 2.39 \mathrm{~mm}$. In case of female,the mean value was $47.58 \mathrm{~mm}$ with standard deviation $( \pm$ ) $1.99 \mathrm{~mm}$ and in lower jaw,the mean value was $41.50 \mathrm{~mm}$ with standard deviation $( \pm) 1.97 \mathrm{~mm}$.

Inter molar arch width (Buccal groove): The mean value of upper jaw, in case of male was $56.50 \mathrm{~mm}$ with standard deviation ( \pm ) $2.23 \mathrm{~mm}$ and in lower jaw, the mean value was $49.78 \mathrm{~mm}$ with standard deviation $( \pm) 2.31 \mathrm{~mm}$. In case of female, the mean value was $54.42 \mathrm{~mm}$ with standard deviation $( \pm) 2.18 \mathrm{~mm}$ and in lower jaw, the mean value was $47.78 \mathrm{~mm}$ with standard deviation ( \pm ) $1.85 \mathrm{~mm}$.

Table; I: Inter molar arch width(mesio buccal cusp tip)

\begin{tabular}{|c|c|c|c|c|}
\hline \multirow[t]{2}{*}{ Parameter } & \multicolumn{2}{|c|}{ Male } & \multicolumn{2}{|c|}{ Female } \\
\hline & Mean (mm) & $\mathrm{SD}(\mathrm{mm})$ & Mean (mm) & $\mathrm{SD}(\mathrm{mm})$ \\
\hline $\begin{array}{l}\text { Upper jaw inter molar arch width from } \\
\text { mesio buccal cusp tip }\end{array}$ & 53.82 & $( \pm) 2.92$ & 51.43 & $( \pm) 3.07$ \\
\hline $\begin{array}{l}\text { Lower jaw inter molar arch width from } \\
\text { mesio buccal cusp tip }\end{array}$ & 46.55 & $( \pm) 3.61$ & 44.31 & $( \pm) 2.74$ \\
\hline
\end{tabular}

Position wise inter molar arch width mesio-buccal cusp tip first molar (L66)

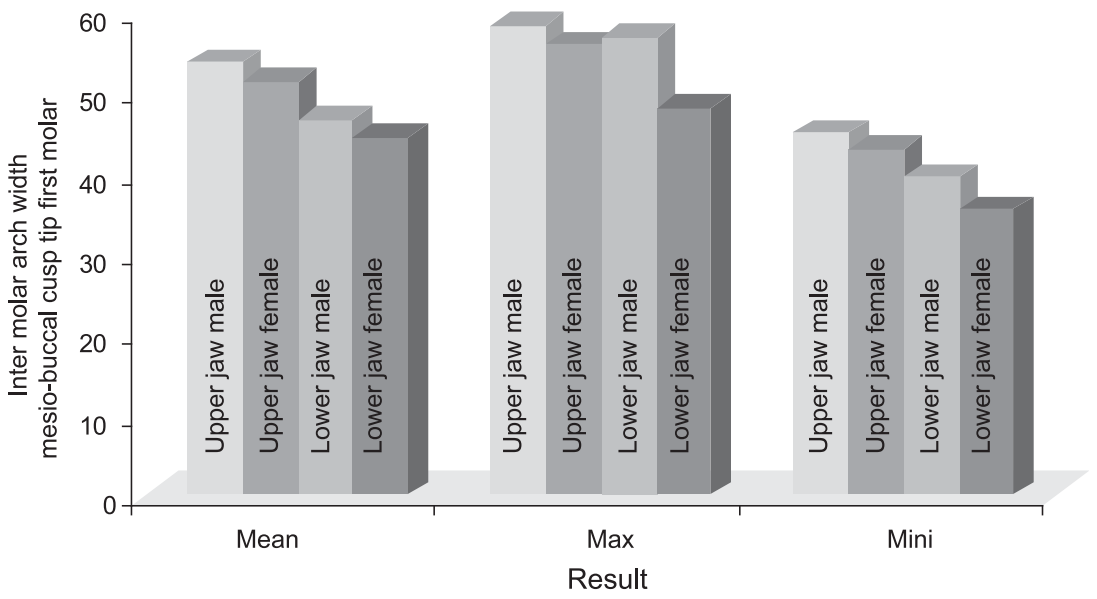

Fig 1: Position wise inter molar arch width -mesiobuccal cusp tip first molar

Table II: Inter molar arch width (central fosse to central fossa)

\begin{tabular}{|c|c|c|c|c|}
\hline \multirow[t]{2}{*}{ Parameter } & \multicolumn{2}{|c|}{ Male } & \multicolumn{2}{|c|}{ Female } \\
\hline & Mean (mm) & $\mathrm{SD}(\mathrm{mm})$ & Mean (mm) & $\mathrm{SD}(\mathrm{mm})$ \\
\hline $\begin{array}{l}\text { Upper jaw intemolar arch width from } \\
\text { central fossa to central fossa }\end{array}$ & 49.18 & $( \pm) 2.14$ & 47.58 & $( \pm) 1.99$ \\
\hline $\begin{array}{l}\text { Lower jaw intemolar arch width from } \\
\text { central fossa to central fossa }\end{array}$ & 42.87 & $( \pm) 2.39$ & 41.50 & $( \pm) 1.97$ \\
\hline
\end{tabular}




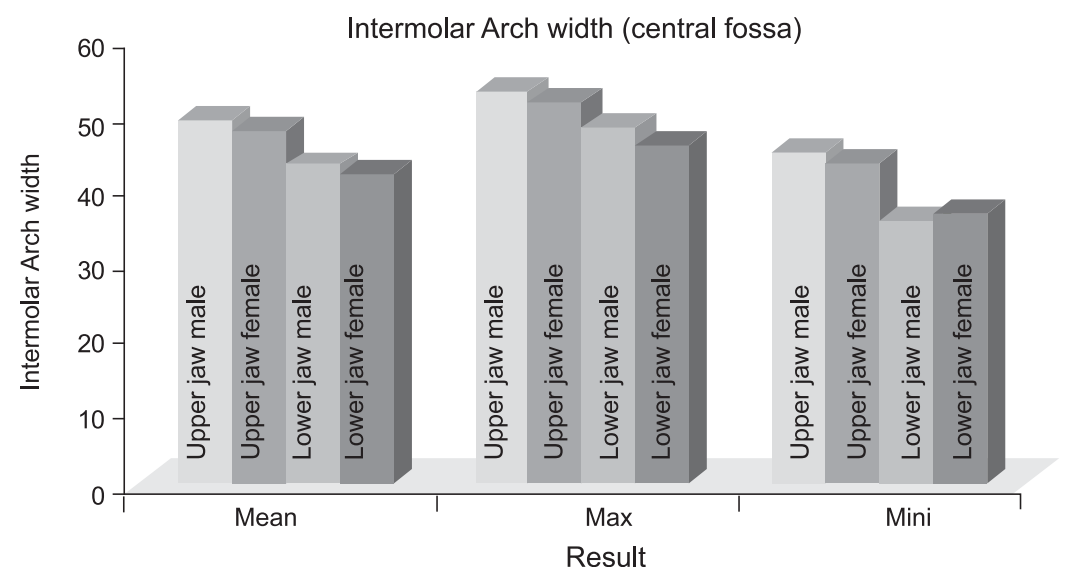

Fig.2: Intermolar Arch width central fossa

Table; III: Inter molar arch width (Buccal groove molar):

\begin{tabular}{|c|c|c|c|c|}
\hline \multirow[t]{2}{*}{ Parameter } & \multicolumn{2}{|c|}{ Male } & \multicolumn{2}{|c|}{ Female } \\
\hline & Mean (mm) & $\overline{\mathrm{SD}(\mathrm{mm})}$ & Mean (mm) & $\overline{\mathrm{SD}(\mathrm{mm})}$ \\
\hline Upper jaw intemolar arch width & 56.50 & $( \pm) 2.23$ & 54.42 & $( \pm) 2.18$ \\
\hline Lower jaw intemolar arch width & 49.78 & $( \pm) 2.31$ & 47.78 & $( \pm) 1.85$ \\
\hline
\end{tabular}

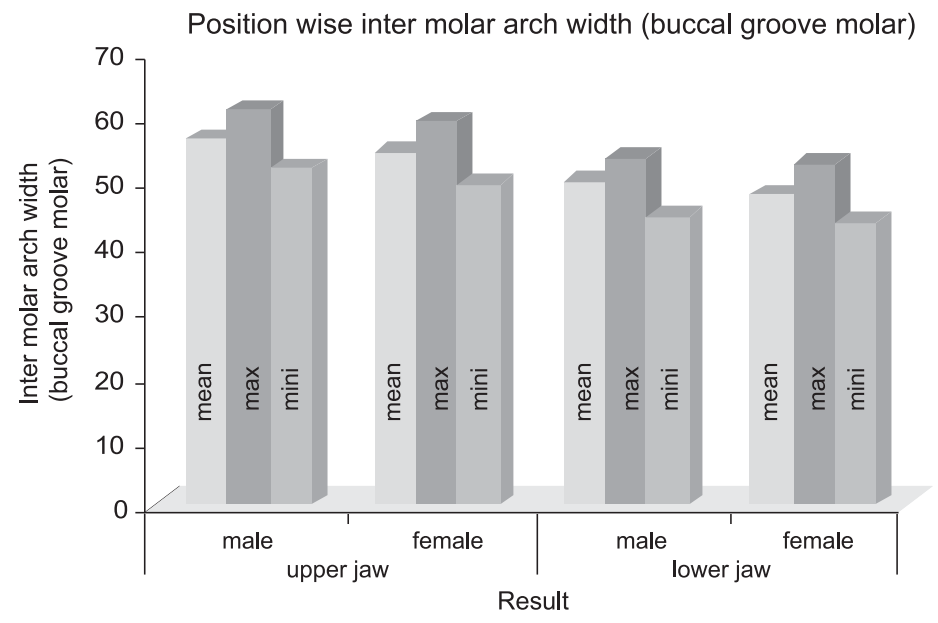

Fig3: Position wise inter molar arch width (buccal groove molar) 


\section{DISCUSSION}

This cross sectional type of study was conducted in the Department of Orthodontics and Dentofacial Orthopedics, Dhaka Dental College and Hospital, Mirpur - 14, Dhaka, to estimate arch width in molar region in normal occlusion. The subject of this study was selected from students of Dhaka dental college. This study correlated with the previous study conducted among the Saudi and Egyptian population sample ${ }^{15}$. This study was also correlate with the study result found among the Indonesian's sample. But, this result was significantly lower than the Australian aborigines sample with same criteria. ${ }^{16}$ This may be due to diet, environmental factors, or physical characteristics that present in the population.

The first molar 1 arch width along the mesiobuccal cusp tip on the occlusal surface in male upper jaw was $38.39 \pm 2.06 \mathrm{~mm}$ and in lower jaw this value was $46.55 \pm 3.61 \mathrm{~mm}$ and in case of female this was $44.31 \pm 2.74 \mathrm{~mm}$. This result was significantly lower than the Australian aborigines and Indonesian sample ${ }^{7}$ All the arch width along the permanent first molar both in upper and in lower jaw were greater in male sample than in female samples. These values were lower than the previous study done on American black and white population. ${ }^{13}$

\section{CONCLUSION}

The idea of a single arch width could not be substantiated in these sample of untreated adults with a normal occlusion. But the results obtained from this preliminary study may be regarded as a milestone in the field of Orthodontic research in Bangladeshi context, which might help the Orthodontists, researchers and relevant practitioners for an effective clinical decision. The Orthodontist who is cognizant and aware of these possible differences while evaluating arch width, will be better prepared to diagnosis and plan treatment more accurately. However, further similar studies are recommended to establish the validity of the work.

\section{REFERENCES}

1. Haq ME. Essentials of orthodontics for dental students.3rd edition. Daarus Salam, Uttara; 2002.

2. Singh G, Varma M.Textbook of Orthodontics. 1st edition .Jaypee, New Delhi; 2004.

3. Sillman JH. Dimentional changes of the dental arches: longitudinal study from birth to 25 years. Am J Orthod 1964; 50:824-42.

4. Lundstrom A. changes in crowding and spacing of the teeth with age.Dent Pract 1968;19:218-24.

5. Howes AE: A polygon of coronal and basal arch dimensions in the horizontal plane. Am J Orthod 1954;40:811.

6. Bolton WA:Disharmony in tooth size and its relation to the analysis and treatment of malocclusion. Angle Orthod 1958;28:113.

7 Bolton WA: The clinical application of a tooth -size analysis. Am j Orthod 1962;48:504.

8. Juneja T, Singh G. Textbook of orthodontics-orthodontic study models.1st edition Jaypee, New Delhi;2004..

11. Hossain MZ. Haque S, Yasmin S, Haq ue A, et al. Prevalence of malocclusion and treatment facilities at Dhaka Dental College and Hospital. J of Oral Health 1994;1:4-6.

12. Niaz A, Kamran C. Prevalence of malocclusion and its aetiological factors. J of Oral Health 1996;2:12-16.

13. Merz ML, Isaacson RJ .Tooth diameters and arch perimeters in a black and a white population . Am J Orthod 1991;53-58.

14. Raberian M, Laumon B, Martin LJ. Dimentions and form of dental arches in subjects with normal occlusions. Am J Othod 1993;104:67-72.

15. Salwa Abd Ei samad Younes. Maxillary arch dimentions in Saudi and Egyptian population . Am J Orthod 1984; 83-88.

16. Robnett JH. Segment concept in arch pattern design. Am J Orthod $1980 ; 77 ; 355-67$

\section{Correspondence}

\section{Dr. Moklesur Rahman, BDS, FCPS}

Lecturer

Dept. of Orthodontics and Dentofacial Orthopedics

Dhaka dental College and Hospital

Mirpur -14, Dhaka- 1206

Mobile : +8801711379555, E-mail : mpino1971@yahoo.com 